\section{Review}

\author{
Correspondence \\ Michael Niederweis \\ mnieder@uab.edu
}

\title{
Nutrient acquisition by mycobacteria
}

\author{
Michael Niederweis
}

Department of Microbiology, University of Alabama at Birmingham, 609 Bevill Biomedical Research
Building, 845 19th Street South, Birmingham, AL 35294, USA

The growth and nutritional requirements of mycobacteria have been intensively studied since the discovery of Mycobacterium tuberculosis more than a century ago. However, the identity of many transporters for essential nutrients of $M$. tuberculosis and other mycobacteria is still unknown despite a wealth of genomic data and the availability of sophisticated genetic tools. Recently, considerable progress has been made in recognizing that two lipid permeability barriers have to be overcome in order for a nutrient molecule to reach the cytoplasm of mycobacteria. Uptake processes are discussed by comparing $M$. tuberculosis with Mycobacterium smegmatis. For example, M. tuberculosis has only five recognizable carbohydrate transporters in the inner membrane, while $M$. smegmatis has 28 such transporters at its disposal. The specificities of inner-membrane transporters for sulfate, phosphate and some amino acids have been determined. Outer-membrane channel proteins in both organisms are thought to contribute to nutrient uptake. In particular, the Msp porins have been shown to be required for uptake of carbohydrates, amino acids and phosphate by $M$. smegmatis. The set of porins also appears to be different for $M$. tuberculosis and M. smegmatis. These differences likely reflect the lifestyles of these mycobacteria and the availability of nutrients in their natural habitats: the soil and the human body. The comprehensive identification and the biochemical and structural characterization of the nutrient transporters of $M$. tuberculosis will not only promote our understanding of the physiology of this important human pathogen, but might also be exploited to improve tuberculosis chemotherapy.

\section{Introduction}

The growth and nutritional requirements of mycobacteria have been intensively studied since the discovery of Mycobacterium tuberculosis (Koch, 1882). These studies have resulted in an overwhelming body of literature on the physiology of mycobacterial metabolism in the years before the dawn of molecular biology (Edson, 1951; Ramakrishnan et al., 1972; Ratledge, 1982). For example, the utilization of many solutes such as carbohydrates, alcohols, carboxy acids, fatty acids and amino acids by mycobacteria was examined by measuring oxygen consumption (Edson, 1951). It is striking that the identity of many transporters for essential nutrients of $M$. tuberculosis and other mycobacteria is still unknown despite considerable progress in the development of genetic methods for mycobacteria (Kana \& Mizrahi, 2004; Machowski et al., 2005). Recently, in particular carbon metabolism of mycobacteria has attracted renewed interest since the observation that $M$. tuberculosis relies on the glyoxylate cycle for survival in mice (McKinney et al., 2000; MunozElias \& McKinney, 2005). This indicates that $M$.

Two supplementary figures showing the genetic organization of $M$. smegmatis carbohydrate transporters of the ABC, PTS, MIP, SSS and MFS protein families are available with the online version of this review. tuberculosis uses lipids as the main carbon source during infection. On the other hand, genes that encode a putative disaccharide transporter were found to be essential for $M$. tuberculosis during the first week of infection (Sassetti \& Rubin, 2003), indicating that $M$. tuberculosis may switch its main carbon source from carbohydrates to lipids with the onset of the adaptive immune response. Obviously, this requires that $M$. tuberculosis has the capacity to take up these particular carbohydrates and lipids. However, both the carbon sources and the corresponding uptake proteins are unknown for $M$. tuberculosis inside the human host. Surprisingly little is known about the identity and properties of many other transporters for essential nutrients, even for in vitro-grown $M$. tuberculosis or for Mycobacterium smegmatis, which is often used as a fastgrowing, non-pathogenic model organism. However, recent progress has been made in understanding the uptake of some nutrients in both M. smegmatis and $M$. tuberculosis. For example, proteins have been identified and characterized that are involved in uptake of several nutrients such as phosphate (Gebhard et al., 2006; Peirs et al., 2005; Vyas et al., 2003; Webb, 2003; Wolschendorf et al., 2007), sulfate (Wooff et al., 2002) and some amino acids (Seth \& Connell, 2000; Talaue et al., 2006). This review focuses primarily on the uptake of solutes that are considered to be major nutrients for mycobacteria. The 
presence of two lipid barriers in mycobacteria imposes considerable constraints for the transport of solutes from the exterior of the cell to the cytoplasm and has important consequences for the physiology and pathogenesis of mycobacteria. Previous reviews have covered inner-membrane transporters of M. tuberculosis (Content et al., 2005). Considering the fact that mycobacteria have elaborated a very efficient permeability barrier outside the inner membrane (Brennan \& Nikaido, 1995; Niederweis, 2003), the current knowledge about nutrient uptake across both inner and outer membranes in mycobacteria is summarized and evaluated. A putative link between outermembrane transport and growth rate of mycobacteria has recently been discussed (Cox \& Cook, 2007).

\section{The cell envelope of mycobacteria}

\section{Permeability barriers in mycobacterial cell envelopes}

Nutrient uptake mechanisms obviously depend on the permeability barriers imposed by the cell envelope. Therefore, it is necessary to review the current status of the research about the cell envelope of mycobacteria. The terms are defined as follows (Beveridge, 1995; Beveridge \& Kadurugamuwa, 1996; Graham et al., 1991): The cell wall consists of the periplasm, the peptidoglycan layer and, for Gram-negative bacteria, the outer membrane. The periplasmic space represents an extracytoplasmic compartment confined between the plasma membrane and an outer structure (outer membrane versus a peptidoglycanteichoic acid-protein network for Gram-negative and Gram-positive bacteria, respectively). The periplasm is composed mostly of soluble components. The cell envelope comprises the inner membrane and the cell wall. The components of the cell envelopes of both Gram-positive and Gram-negative bacteria have recently been visualized by cryo-electron microscopy (Matias et al., 2003; Matias \& Beveridge, 2005, 2006).

In microbiology textbooks, mycobacteria are still classified as Gram-positive bacteria. However, it is well documented that mycobacteria, unlike other Gram-positive bacteria, have evolved a very complex cell wall, comprising an arabinogalactan-peptidoglycan polymer with covalently bound mycolic acids of considerable size (up to 90 carbon atoms), a large variety of extractable lipids (Barry et al., 1998; Daffé \& Draper, 1998) and pore-forming proteins (Niederweis, 2003). Most of the mycobacterial lipids are constituents of the cell envelope, which provides an extraordinarily efficient permeability barrier to noxious compounds, rendering mycobacteria intrinsically resistant to many drugs (Brennan \& Nikaido, 1995). Due to the paramount medical importance of $M$. tuberculosis, the ultrastructure of mycobacterial cell envelopes has been intensively studied for decades by electron microscopy. A thick, electron-transparent zone has been observed in the cell wall in stained thin sections of many mycobacterial species (Mineda et al., 1998; Paul \& Beveridge, 1992) and was shown to comprise lipids (Paul \& Beveridge, 1994). To account for the remarkable efficiency of the mycobacterial cell wall as a permeability barrier, Minnikin (1982) originally proposed a model (Fig. 1) in which the mycolic acids are covalently bound to the arabinogalactanpeptidoglycan co-polymer and form the inner leaflet of an asymmetrical bilayer. Other lipids extractable by organic solvents were thought to form the outer leaflet of this outer bilayer. X-ray diffraction studies of mycobacterial cell walls showed that the mycolic acids are oriented parallel to each other and perpendicular to the plane of the cell envelope (Nikaido et al., 1993). This provided experimental support for some fundamental aspects of the Minnikin model. Mutants and treatments affecting mycolic acid biosynthesis and the production of extractable lipids showed an increase of cell wall permeability and a drastic decrease of virulence, underlining the importance of the integrity of the cell wall for intracellular survival of M. tuberculosis (Barry et al., 1998). These indirect structural, biochemical and genetic

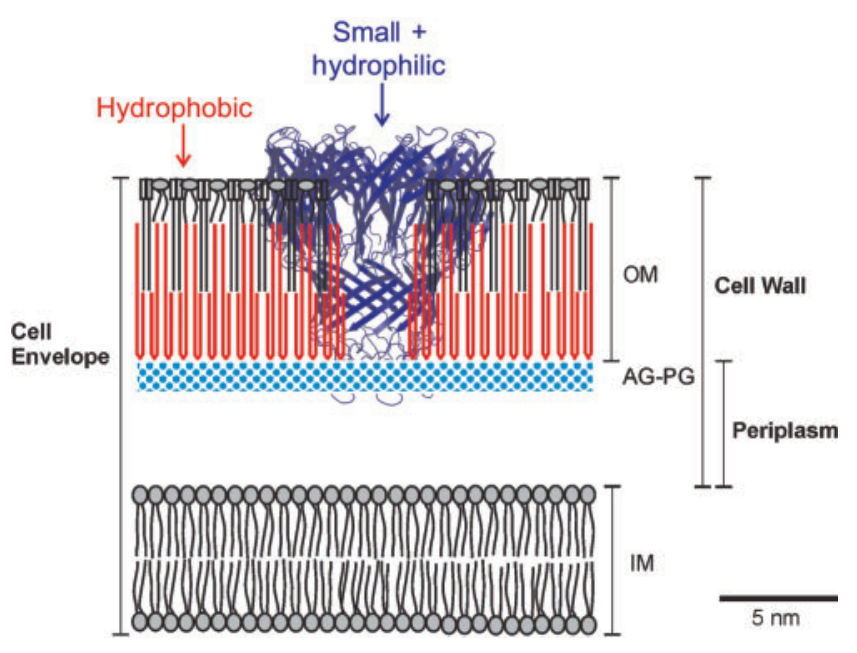

Fig. 1. Transport processes across the mycobacterial cell envelope: schematic representation of the mycobacterial cell envelope consisting of the inner membrane (IM) and the cell wall. This representation is based on the model proposed by Minnikin (1982). Mycolic acids are covalently linked to the arabinogalactanpeptidoglycan (AG-PG) co-polymer and are thought to contribute to the inner leaflet of the asymmetrical outer membrane (OM). A variety of extractable lipids presumably form the outer leaflet of the outer membrane. Note that no experimental data exist for either the spatial distribution of the extractable lipids, or the confirmations and exact locations of the mycolic acids. The porin MspA mediates the uptake of small and hydrophilic nutrients such as sugars (Stephan et al., 2005) and phosphates (Wolschendorf et al., 2007) across the outer membrane of $M$. smegmatis. The representation of MspA is based on its crystal structure (Faller et al., 2004) and was created using the visualization software PyMol (DeLano Scientific). The MspA channel is $9.6 \mathrm{~nm}$ long. Approximately $7 \mathrm{~nm}$ of the MspA surface is inaccessible to hydrophilic reagents in M. smegmatis (Mahfoud et al., 2006). Hydrophobic compounds are assumed to diffuse directly across the outer membrane. The dimensions are approximately to scale. 
data are consistent with the existence of an outer lipid bilayer as proposed by Minnikin (1982). However, this model (Fig. 1) faced criticism mainly because electron microscopy of mycobacteria, in particular thin sections thereof, never showed evidence for an additional, outer lipid bilayer (Daffé \& Draper, 1998; Draper, 1998). In addition, the exact localization of the extractable lipids and of the mycolic acids is unknown. One of the difficulties in providing additional experimental evidence for this model is the fact that lipid membranes are notoriously poorly preserved during chemical fixation and plastic embedding (Beveridge, 1999). Thus, direct evidence for an outer lipid bilayer in mycobacteria is lacking. Consequently, a periplasmic space as defined above has been regarded as hypothetical for mycobacteria (Daffé \& Draper, 1998; Etienne et al., 2005). Recently, cryo-electron tomography of intact M. smegmatis and Mycobacterium bovis BCG cells revealed two lipid membranes. This is the first visualization of native outer membranes in mycobacteria (Hoffmann et al., 2008). Biologically important consequences are that mycobacteria possess a periplasmic space defined by two membranes, analogous to the situation in Gram-negative bacteria and have periplasmic and outer-membrane proteins that functionalize these cellular compartments.

\section{Principal nutrient pathways across the mycobacterial cell envelope}

The unique mycolic acid layer is an extremely efficient permeability barrier protecting the cell from toxic compounds and is generally thought to be the major determinant of the intrinsic resistance of mycobacteria to most common antibiotics, chemotherapeutic agents and chemical disinfectants (Brennan \& Nikaido, 1995). The mycolic acid layer is functionally and structurally analogous to the outer membrane of Gram-negative bacteria, a similarity that merits a more detailed comparison. Three general and several specific pathways for transport across the outer membrane of Gram-negative bacteria exist. (i) Hydrophobic compounds penetrate the membrane via the lipid pathway by temporarily dissolving in the lipid bilayer. (ii) Small and hydrophilic compounds diffuse through water-filled protein channels called porins (Nikaido, 1994). Some of these diffusion channels show specificity towards certain classes of compounds such as maltodextrin (Dumas et al., 2000) or nucleosides (Maier et al., 1988). (iii) Polycationic compounds are thought to disorganize the outer membrane, thereby mediating their own uptake in a process termed 'self-promoted uptake' (Hancock et al., 1991). (iv) Certain compounds are specifically taken up by transporter proteins such as FhuA and FepA, which transport iron-loaded siderophores in an energy-dependent process across the outer membrane of Escherichia coli (Braun \& Killmann, 1999). The nutrient molecules that have crossed the outer membrane need to pass through the periplasm. The mechanisms of these transport processes in M. tuberculosis are not known. After passage through the periplasm nutrients are taken up across the inner membrane by specific transporter proteins, often against a concentration gradient, using cellular energy. These inner-membrane transporters of $M$. tuberculosis have been the focus of a recent review (Content et al., 2005).

\section{Transport across mycobacterial outer membranes Porin-mediated diffusion of hydrophilic solutes}

Porins are defined as non-specific protein channels in bacterial outer membranes that enable the influx of hydrophilic solutes (Nikaido, 2003). Channel-forming proteins that are functionally similar to porins of Gramnegative bacteria have been observed in many mycobacteria (Niederweis, 2003) and other closely related genera such as corynebacteria. MspA was discovered as the first porin of M. smegmatis (Niederweis et al., 1999). Deletion of mspA reduced the outer-membrane permeability of $M$. smegmatis to cephaloridine and glucose nine- and fourfold, respectively (Stahl et al., 2001). These results show that MspA is the major general diffusion pathway for hydrophilic solutes in M. smegmatis. Consecutive deletions of the two porin genes $m s p A$ and $m s p C$ reduced the number of pores 15 -fold compared to wild-type M. smegmatis. The loss of porins lowered the permeability for glucose 75 -fold and, concomitantly, the growth rate of M. smegmatis on plates and in liquid medium dropped drastically (Stephan et al., 2005). This showed for the first time that the porinmediated influx of hydrophilic nutrients limited the growth rate of porin mutants. However, it is unknown which and how many nutrients are in low supply in the $M$. smegmatis porin mutants. Since MspA could not be expressed in $M$. smegmatis above wild-type levels (Stephan et al., 2005), it is also not clear whether the influx of nutrients really limits the growth rate of wild-type mycobacteria as suggested earlier (Jarlier \& Nikaido, 1990). The fact that the lack of the MspA and MspC porins also caused a reduced uptake of phosphates and slower growth on low-phosphate plates (Wolschendorf et al., 2007) indeed suggested that the slow uptake of essential hydrophilic nutrients other than the carbon source may also contribute to the slow growth of M. smegmatis porin mutants.

The crystal structure of MspA represents the first such structure of any mycobacterial outer-membrane protein (Faller et al., 2004). The mere existence of these hydrophobic integral pore proteins provides strong, albeit indirect, support for the existence of an outer membrane in mycobacteria because proteins with open channels in the cytoplasmic membrane would be deterimental for any cell for at least two reasons: first, open pores in the inner membrane would lead to an immediate breakdown of the proton gradient and deprive the cell of energy; and second, small hydrophilic solutes such as many metabolic intermediates or nutrients would leak out of the cell. The crystal structure of MspA revealed an octameric goblet-like conformation with a single central channel $10 \mathrm{~nm}$ in length (Faller et al., 2004). This structure is different from 


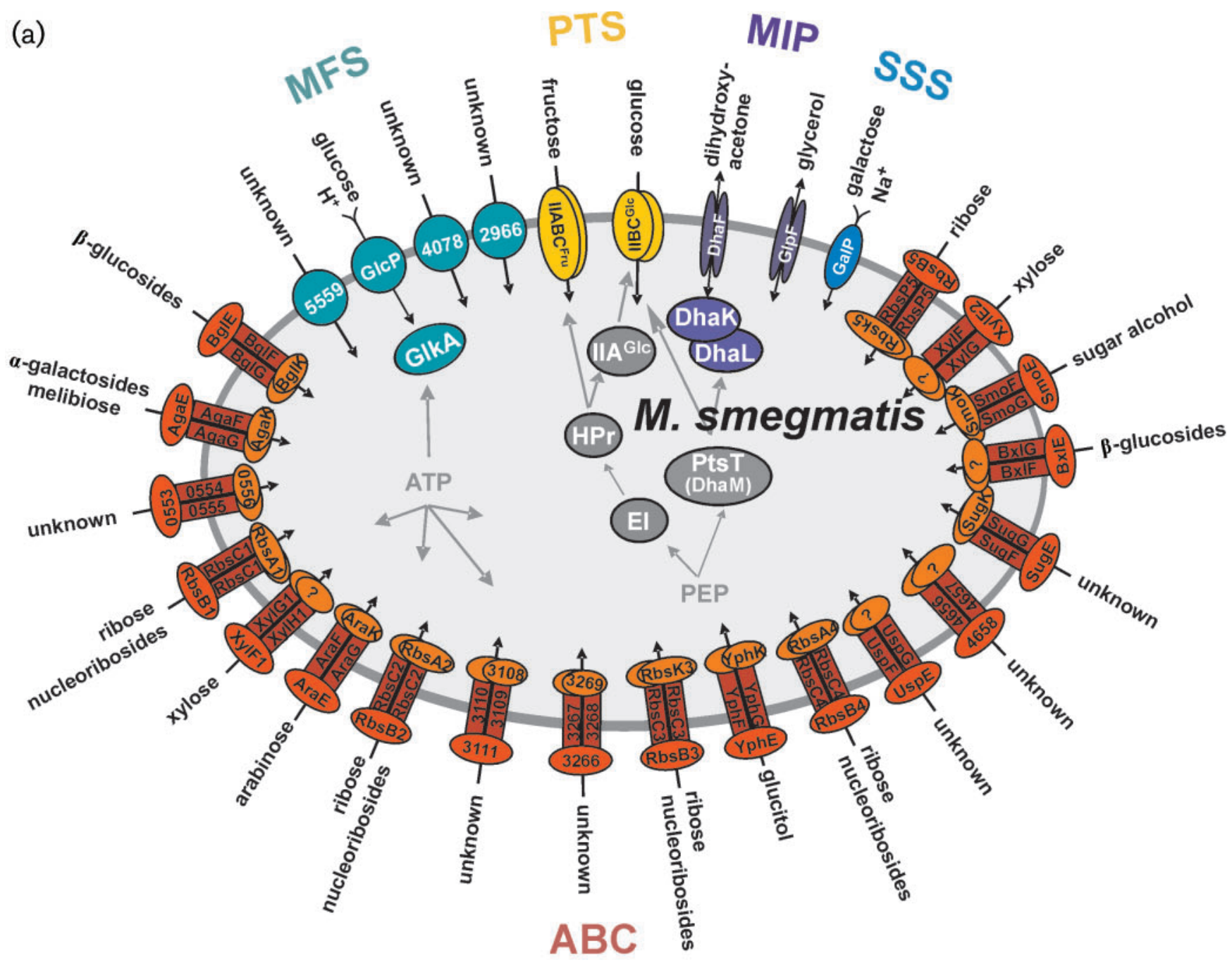

(b)

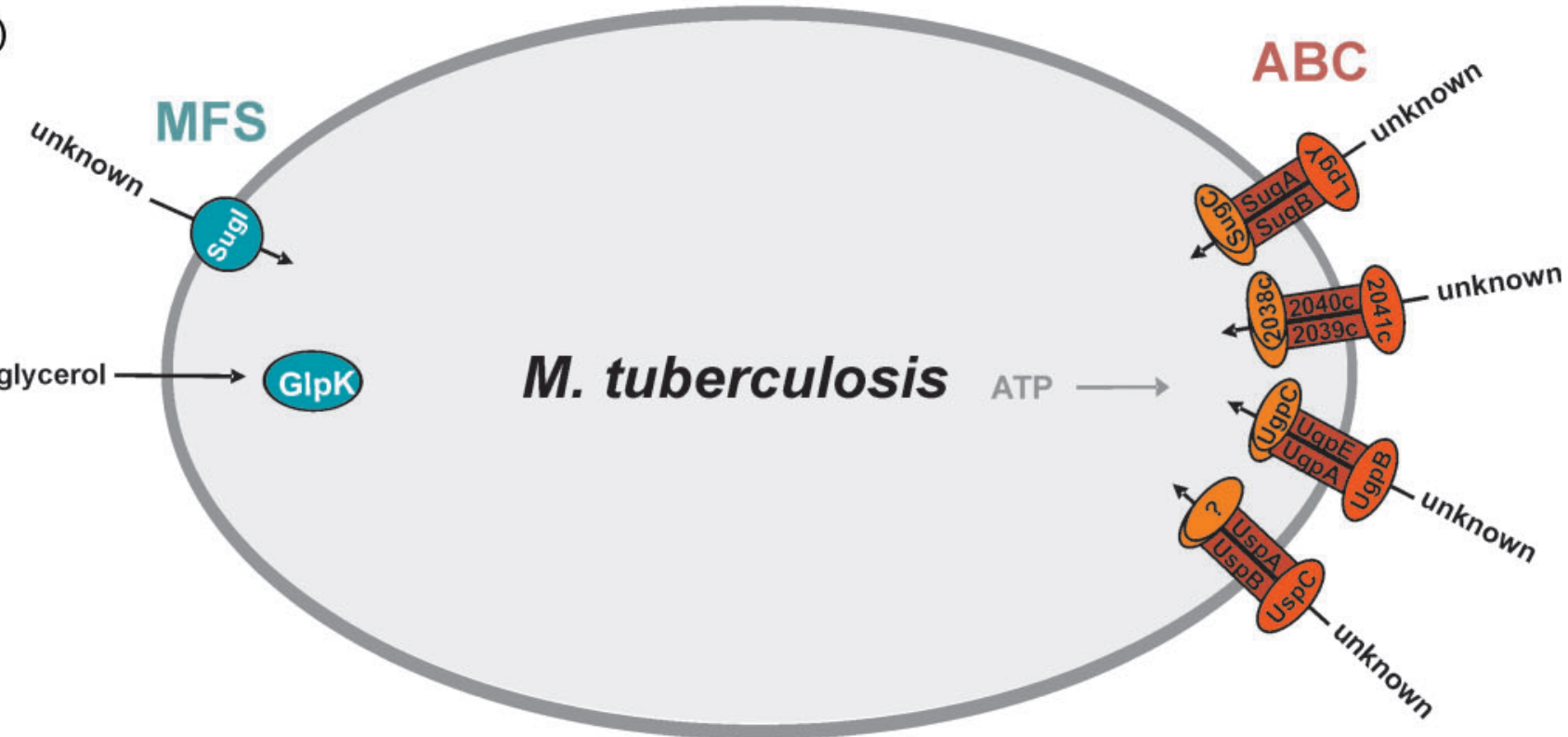


Fig. 2. Transporters for uptake of carbohydrates across the inner membrane of (a) M. smegmatis and (b) M. tuberculosis. Shown are the transport proteins of the ATP-binding cassette (ABC, red), phosphotransferase system (PTS, yellow), major facilitator superfamily (MFS, green), major intrinsic protein family (MIP, dark blue) and the sodium solute superfamily (SSS, light blue). The derived putative substrates are inferred from in silico analyses in combination with experimental data (Titgemeyer et al., 2007). Systems are denoted by the protein name instead of their locus tags (MSMEG_XXXX) if the substrates have been experimentally verified or were predicted with a high likelihood. Note that the outer membranes of M. smegmatis and $M$. tuberculosis have been omitted for clarity.

that of the trimeric porins of Gram-negative bacteria, which have one pore per monomer and are approximately $5 \mathrm{~nm}$ long (Koebnik et al., 2000). Its structural features define MspA as the founding member of a new class of outer-membrane proteins. The crystal structure also revealed that the constriction zone of MspA consists of 16 aspartates (D90/D91). Thus, the zone of MspA with the smallest diameter is highly negatively charged (Faller et al., 2004). This most likely explains the previously observed preference of MspA for cations (Niederweis et al., 1999). The MspA pore provides an example of how outermembrane transport proteins can contribute to the selectivity of mycobacteria to particular nutrients.

The existence of channel-forming proteins in M. tuberculosis and in M. bovis BCG has been demonstrated (Kartmann et al., 1999; Lichtinger et al., 1999; Senaratne et al., 1998). Uptake of serine but not of glycine was reduced in an ompATb mutant compared to wild-type $M$. tuberculosis. This was interpreted as proof that OmpATb is a porin, consistent with its apparent channel-forming activity in vitro (Raynaud et al., 2002b). However, the overall permeability of the outer membrane of $M$. tuberculosis was reduced at $\mathrm{pH} 5.5$ compared to $\mathrm{pH} 7.2$, although the levels of OmpATb in the outer membrane were strongly increased (Raynaud et al., 2002b). Considering these contradictory results, it is doubtful that OmpATb has significant porin function in M. tuberculosis (Niederweis, 2003). The recent observation that a central domain of approximately 150 amino acids is sufficient for the channel activity of OmpATb in vitro does not contribute to the understanding of its biological functions (Molle et al., 2006). Pore-forming proteins of $M$. tuberculosis other than OmpATb are not yet known.

\section{Direct diffusion of hydrophobic solutes through the cell membranes}

Hydrophobic molecules, in particular nonelectrolytes, can easily diffuse through phospholipid bilayers. However, the lipopolysaccharide-containing outer membrane of Gramnegative bacteria constitutes a considerable permeability barrier that does not allow the penetration of even extremely hydrophobic $\beta$-lactam antibiotics (Nikaido et al., 1983). The lipids in mycobacterial cell walls are likely to be organized in a very unusual, asymmetrical bilayer (Nikaido et al., 1993). Differential scanning calorimetry showed that the lipids in mycobacterial cell walls have very high phase transition temperatures in the range of $60-70{ }^{\circ} \mathrm{C}$. This is suggestive of a lipid domain of extremely low fluidity (Liu et al., 1995). Isolated cell walls of corynebacteria, which contain much shorter corynemycolic acids, displayed a much lower temperature transition, suggesting that the fluidity of this lipid bilayer is mainly determined by the mycolic acids. Since direct diffusion of a hydrophobic molecule through a lipid membrane requires that it is dissolved in the lipid phase, the permeability of a particular membrane is directly correlated with its fluidity. This has been demonstrated directly by Nikaido and coworkers (Liu et al., 1996). It is concluded that the mycobacterial outer membrane presents a strong permeability barrier for hydrophobic molecules. On the other hand, there is emerging evidence that fatty acids rather than carbohydrates might be the dominant carbon source of $M$. tuberculosis after the onset of the immune response. This includes the requirement for isocitrate lyase for growth and persistence of $M$. tuberculosis in macrophages and in mice (McKinney et al., 2000), and the induction of expression of genes encoding enzymes involved in the $\beta$-oxidation of fatty acids in macrophages (Schnappinger et al., 2003) and mice (Dubnau et al., 2005; Timm et al., 2003). However, the sources and the types of fatty acids that may be utilized by $M$. tuberculosis, as well as the uptake pathways, are unknown.

\section{Transport across the mycobacterial inner membrane}

\section{Transporters of carbohydrates}

It has been widely documented that the soil bacterium $M$. smegmatis can grow on many carbon sources such as polyols, pentoses and hexoses (Edson, 1951; Franke \& Schillinger, 1944; Izumori et al., 1976). A recent comprehensive analysis of carbohydrate uptake systems revealed that M. smegmatis has 28 putative carbohydrate transporters (Titgemeyer et al., 2007). The majority of sugar transport systems (19/28) in M. smegmatis belong to the ATP-binding cassette (ABC) transporter family (Fig. 2a). M. smegmatis further possesses one putative glycerol facilitator of the major intrinsic protein (MIP) family, four sugar permeases of the major facilitator superfamily (MFS), of which one was assigned as a glucose transporter, and one galactose permease of the sodium solute superfamily (SSS). Thus, inner-membrane transport systems for polyols, pentoses and hexoses are predicted to exist in M. smegmatis (Fig. 2a; see also Supplementary Figs S1 and S2, available with the online version of this review). 
Table 1. Inner-membrane sugar transporters of $M$. smegmatis

\begin{tabular}{|c|c|c|c|c|c|}
\hline & $\begin{array}{l}\text { Family and predicted } \\
\text { substrate }(s)\end{array}$ & Gene designations & Locus tag* & $\begin{array}{l}\text { Representative homologues } \dagger / \\
\text { comments }\end{array}$ & References $\ddagger$ \\
\hline 1 & $\begin{array}{l}\mathrm{ABC} \\
\beta \text {-Glucosides, } \\
\text { chitobiose, } \\
\text { disaccharides }\end{array}$ & $\begin{array}{l}\text { nagB1 bglA bglR sugK } \\
\text { bglEFGK }\end{array}$ & $0501-0508$ & $\begin{array}{l}\text { nagB SCO5236, bgl SCO0670, deoR, } \\
\text { rbsK E. coli, abcEFG } \\
\text { genes are distantly related to many } \\
\text { ABC permease genes, } m s i K \text { SCO } 4240\end{array}$ & Bertram et al. (2004), S, C \\
\hline 2 & $\begin{array}{l}\alpha \text {-Galactosides, } \\
\text { melibiose }\end{array}$ & agaRZSXPAEFGK mspB & 0509-0517 & $\begin{array}{l}\text { SCO5848-5851, SCO0538-0541, } \\
\text { msiK SCO } 4240\end{array}$ & $\begin{array}{l}\text { Bertram et al. (2004); } \\
\text { Brinkkötter } \text { et al. (2000), S }\end{array}$ \\
\hline 3 & Unknown & $a b c E F G K$ & $0553-0556$ & $\begin{array}{l}\text { Distant similarity to many } \mathrm{ABC} \\
\text { permease genes }\end{array}$ & $\mathrm{S}, \mathrm{C}$ \\
\hline 4 & Ribose, xylose & $\begin{array}{l}r b s A 1 C 1 B 1 \text { gatY sugK rbsR1 } \\
\text { pfkB }\end{array}$ & $1372-1378$ & $\begin{array}{l}\text { SCO6009-6011, gatY SCO5852, pfkB } \\
\text { SCO3197, distantly related to ribose } \\
\text { and xylose ABC transporters }\end{array}$ & $\begin{array}{l}\text { Bell et al. (1986); Bertram } \\
\text { et al. (2004), S, C, T, B }\end{array}$ \\
\hline 5 & Xylose & $x y l F 2 G 2 H 2$ & $1704-1706$ & E. coli $x y l F G H$ & $\begin{array}{l}\text { Daley et al. (2005); Sumiya } \\
\text { et al. (1995), C }\end{array}$ \\
\hline 6 & Arabinose & pho araR araGFKEBDA & $1707-1715$ & E. coli $y t f$ operon, B. subtilis araABD & Sa-Nogueira et al. (1997), B, C \\
\hline 7 & $\begin{array}{l}\text { Ribose, } \\
\text { ribonucleosides }\end{array}$ & $\begin{array}{l}\text { gap pgk tpiA secG urf rscA } \\
\text { deoC rbsC2A2rbsR2 sugK } \\
\text { sugD rbsB2 ppc pgl opcA } \\
\text { zwf tal tkt }\end{array}$ & $3084-3103$ & $\begin{array}{l}\text { rbsH SCO2747, rbsA SCO2746, rbsB } \\
\text { E. coli }\end{array}$ & $\begin{array}{l}\text { Bell et al. (1986); Bertram } \\
\text { et al. (2004), S, C }\end{array}$ \\
\hline 8 & Unknown & $a b c K G F E$ fabG sugK & $3108-3113$ & $\begin{array}{l}\text { Distant similarity to many } \mathrm{ABC} \\
\text { permease genes }\end{array}$ & Bertram et al. (2004), S, C \\
\hline 9 & Unknown & $\begin{array}{l}a b c R \text { sugK } a b c E F G K 1 K 2 \\
\text { sugK rpiB }\end{array}$ & $3264-3272$ & $\begin{array}{l}\text { Distant similarity to many ABC } \\
\text { permease genes, SCO0580, E. } \\
\text { coli rpiB }\end{array}$ & $\begin{array}{l}\text { Bertram et al. (2004); Sørensen } \\
\text { \& Hove-Jensen (1996), S, C }\end{array}$ \\
\hline 10 & Ribose & $r b s B 3 R 3 C 3 A 3$ & $3598-3602$ & SCO 2747, B. subtilis ribose operon & Woodson \& Devine (1994) \\
\hline 11 & Sorbitol & $y p h R E K F B$ & $3998-4002$ & E. coli yph operon & Bertram et al. (2004), C \\
\hline 12 & Ribose & rbsA4C4B4R4 & $4170-4174$ & E. coli ribose operon $r b s C B R$ & Bell et al. (1986), C \\
\hline 13 & Unknown & uspGFE & $4466-4468$ & M. tuberculosis usp operon & Braibant et al. (2000), T \\
\hline 14 & Unknown & $a b c R F G E$ & $4655-4658$ & $\begin{array}{l}\text { Distant similar to many } \mathrm{ABC} \\
\text { permease genes }\end{array}$ & $S, C$ \\
\hline 15 & Unknown & sugKGFE & $5058-5061$ & M. tuberculosis sug operon & Braibant et al. (2000), T \\
\hline 16 & $\beta$-Xyloside & bglG bxlRAEFG & $5142-5147$ & S. coelicolor bxlEFG2 & Bertram et al. (2004) \\
\hline 17 & Sugar alcohol & SMoKGFER & $5571-5574$ & S. coelicolor smo operon & Bertram et al. (2004) \\
\hline 18 & Xylose & $x y l G 1 F 1 E 1 A 1 R 1$ & $6018-6022$ & E. coli $x y l$ operon & Sumiya et al. (1995) \\
\hline 19 & $\begin{array}{l}\text { Ribose } \\
\text { PTS }\end{array}$ & rbsR5P5K5G5F5E5 & $6798-6805$ & SCO0723, SAV5702, SCO 2747 & Bertram et al. (2004), S, C \\
\hline 20 & Fructose & $p t s H$ fruAKR ptsI & $0084-0088$ & S. coelicolor ptsH fruAKR ptsI & $\begin{array}{l}\text { Bertram et al. (2004); Nothaft et } \\
\text { al. (2003), S }\end{array}$ \\
\hline 21 & $\begin{array}{l}N \text {-Acetylglucosamine } \\
\text { glucose, trehalose }\end{array}$ & ptsG crr nagB2A ptsR & $2116-2120$ & S. coelicolor nagE2 $\mathrm{crr}$ nagAB & $\begin{array}{l}\text { Bentley et al. (2002); Nothaft et } \\
\text { al. (2003) }\end{array}$ \\
\hline 22 & Dihydroxyacetone & ptsT dhaLKFR & $2121-2125$ & $\begin{array}{l}\text { S. coelicolor gyl operon, E. coli } \\
\text { dhaKLM }\end{array}$ & $\begin{array}{l}\text { Bertram et al. (2004); Gutknecht } \\
\text { et al. (2001), S, C }\end{array}$ \\
\hline 23 & $\begin{array}{l}\text { MIP } \\
\text { Glycerol } \\
\text { SSS }\end{array}$ & $g l p K 2 R F K 1 D$ & $6756-6760$ & S. coelicolor gyl operon & Bertram et al. (2004), S \\
\hline 24 & Galactose & galPRTK & $3689-3692$ & S. coelicolor gal operon & Bertram et al. (2004) \\
\hline
\end{tabular}


Table 1. cont.

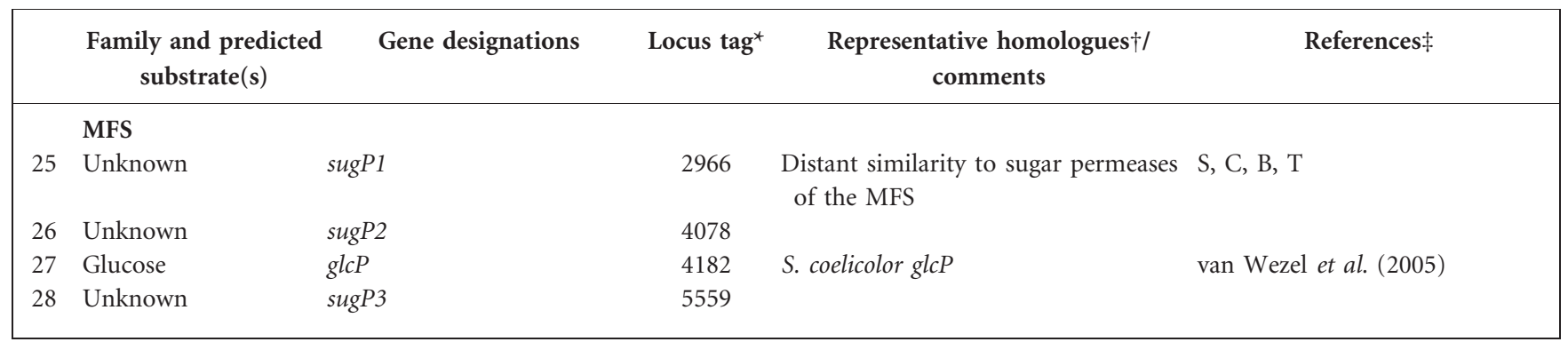

*Only the numbers of the locus tags msmeg_XXXX of the M. smegmatis $\mathrm{mc}^{2} 155$ genome are shown. Locus tags are taken from the revised genome annotation by TIGR (http://www.tigr.org).

$\dagger$ This column contains information on representative homologues for which experimental information is available.

$¥$ The following genome servers were used for BLASTP analysis: B, B. subtilis (http://genolist.pasteur.fr/SubtiList); C, E. coli (http://genolist.pasteur.fr/ Colibri); S, S. coelicolor (www.avermitilis.ls.kitasato-u.ac.jp/blast_local/index.html); T, M. tuberculosis (http://genolist.pasteur.fr/TubercuList).

M. smegmatis did not grow on lactose, maltose and sucrose as a sole carbon source (Titgemeyer et al., 2007). Franke \& Schillinger (1944) obtained the same result for lactose and maltose, but observed respiration of $M$. smegmatis in the presence of sucrose. $M$. smegmatis has at least three innermembrane transport systems with significant similarities to other bacterial disaccharide transporters (Table 1, Fig. S1). However, the substrate specificities of the transporters encoded by msmeg0501-0508 and msmeg0509-0517 are not known. Growth of bacteria on disaccharides as sole carbon sources requires enzymes that cleave the disaccharide and release the monosaccharides for further metabolism. The absence of proteins similar to known bacterial $\beta$-Dgalactosidases (LacZ of E. coli, BgaB of Bacillus circulans, MbgA of Bacillus megaterium, LacA of Streptomyces coelicolor) provides a molecular explanation for the inability of $M$. smegmatis to utilize lactose as a sole carbon source. By contrast, $M$. smegmatis has six homologues (MSMEG3191, 3577, 4901, 4902, 4685, 6477) of MalL of Bacillus subtilis, which hydrolyses maltose, longer maltodextrins up to maltohexose, isomaltose and sucrose (Schönert et al., 1999), and of the cytoplasmic trehalase TreC of E. coli, which cleaves trehalose 6-phosphate (Rimmele \& Boos, 1994). It is conceivable that these enzymes are used in trehalose metabolism, considering the unusual importance of trehalose in mycobacteria (Murphy et al., 2005; Woodruff et al., 2004) and the observation that trehalose was the only disaccharide that was used by $M$. smegmatis as a sole carbon source. However, it cannot be excluded that some of the enzymes with similarities to TreC and MalF have roles in pathways distinct from trehalose metabolism.

Bioinformatic analysis of the genome of $M$. tuberculosis $\mathrm{H} 37 \mathrm{Rv}$ revealed four ABC-type transporters and one permease of the MFS class for carbohydrates (Titgemeyer et al., 2007) (Fig. 2b). These ABC transporters have been described earlier in a global analysis of the M. tuberculosis genome (Braibant et al., 2000; Content et al., 2005). It is obvious that $M$. tuberculosis is poorly equipped with carbohydrate transport systems in comparison to $M$. smegmatis. Two of the operons, the $\operatorname{lpg} Y-\operatorname{sug} A B C$ and the usp $A B C$ operons, are highly conserved between the two species. The proteins of the $\mathrm{ABC}^{\mathrm{Sug}}$ and of the $\mathrm{ABC}^{\mathrm{Usp}}$ systems share between $62 \%$ and $80 \%$ similar amino acids, compared to only $25-30 \%$ similar amino acids for the $\mathrm{ABC}^{\mathrm{Ugp}}$ and the Rv2038c/Rv2039c/Rv2040c/Rv2041c systems. The similarities of all four ABC systems to known transporters outside the genus Mycobacterium is so low $(<25 \%)$ that substrates of these transporters cannot be predicted (Titgemeyer et al., 2007).

The $\mathrm{ABC}^{\text {Sug }}$ sugar transport system was predicted to be essential for virulence of M. tuberculosis in mice based on transposon site hybridization (TraSH) experiments (Sassetti \& Rubin, 2003). Previously, it was suggested that this permease may transport maltose or maltodextrins (Borich et al., 2000; Braibant et al., 2000). However, the similarities both of $\mathrm{ABC}^{\mathrm{Sug}}$ and of the corresponding substrate-binding protein LpgY to the maltose transporters and periplasmic maltose-binding proteins MalE of E. coli and S. coelicolor are very low $(<25 \%)$. Thus, it is questionable whether maltose is the substrate of $\mathrm{ABC}^{\text {Sug }}$. This conclusion is supported by the fact that neither $M$. smegmatis, which has a highly similar $\mathrm{ABC}^{\text {Sug }}$ system, nor M. tuberculosis (Edson, 1951) grows on maltose as a sole carbon source. It has to be noted that similar uncertainties exist about the substrate specificities of the four other carbohydrate uptake systems of $M$. tuberculosis, including the $\mathrm{ABC}^{\mathrm{Usp}}$ transporter that was proposed to transport snglycerol 3-phosphate based on low protein similarities (Braibant et al., 2000; Content et al., 2005). The SugI transporter of the MFS class shows distant sequence similarity to the glucose permease GlcP $(28 \%)$ of $S$. coelicolor and to the galactose (GalP, $24 \%$ ) and arabinose (AraE, $24 \%$ ) transporters of E. coli. Thus, the SugI system may transport a monosaccharide.

Glycerol is used as the standard carbon source to grow $M$. tuberculosis; however, no uptake system is known or 
apparent by sequence similarity (Titgemeyer et al., 2007). Since $M$. tuberculosis grows with a generation time of $24 \mathrm{~h}$ and it has been shown that glycerol can directly diffuse through lipid membranes both in vitro (Paula et al., 1996) and in vivo (Eze \& McElhaney, 1981), it is conceivable that the rate of glycerol intake by passive diffusion may be sufficient for growth. Incoming glycerol would then be converted by glycerol kinase (GlpK) to glycerol 3phosphate to enter the route of central carbon metabolism (Fig. 2b). M. tuberculosis has one putative glycerol kinase that shows a high similarity to the two glycerol kinases of M. smegmatis (MSMEG6759, 77\%, and MSMEG6756, $57 \%)$ and to the two glycerol kinases from S. coelicolor SCO0509 (75\%) and SCO1660 (59\%).

Comparison of inner-membrane sugar transporters of M. smegmatis and M. tuberculosis. The analysis of the carbohydrate uptake proteins in the genomes of $M$. smegmatis and $M$. tuberculosis confirms the very early phenotypic observations that the saprophytic mycobacteria have a much broader spectrum of substrates that they can use as sole carbon and energy sources (Edson, 1951). It is striking that the genome of $M$. tuberculosis has only five permeases for carbohydrate uptake compared to the 28 of M. smegmatis. This suggests that the phagosome does not provide an environment rich in diverse sugars. The tantalizing conclusion is that an experimental analysis of the substrate specificity of the inner-membrane carbohydrate transporters of $M$. tuberculosis may reveal the carbon sources available in the phagosome of human macrophages and/or in other cellular hideouts of $M$. tuberculosis inside the human body.

\section{Transporters of lipids}

Several lines of evidence strongly suggest that $M$. tuberculosis switches from a carbohydrate to a fat diet after the onset of the adaptive immune response. (i) Biochemical studies suggest that in chronically infected lung tissues, fatty acids may be a major source of carbon and energy for M. tuberculosis (Wheeler et al., 1990). (ii) During the first 10 days of infection of mice, $M$. tuberculosis requires the sugar transporter SugAB for survival (Sassetti \& Rubin, 2003). Thereafter, enzymes such as isocitrate lyase and malate synthases are essential for virulence (McKinney et al., 2000). This indicates that lipids are the major carbon and energy source of M. tuberculosis because the glyoxylate shunt is required for running the citric acid cycle on acetate, which is produced by degradation of lipids through $\beta$-oxidation. (iii) $M$. tuberculosis possesses four genes encoding putative phospholipases $\mathrm{C}, p l c A, p l c B, p l c C$ and plcD. These genes are required for virulence of $M$. tuberculosis in mice (Raynaud et al., 2002a). The fact that the phospholipases $\mathrm{C}$ are attached to the cell wall by lipid anchors argues for a role of these enzymes in the controlled release of fatty acids, probably from phospholipids of the phagosomal membrane. However, while several proteins have been identified in $M$. tuberculosis as being involved in the transport of lipids from the cytoplasm to the periplasm (Jackson et al., 2007), the proteins involved in the transport of lipids across the outer membrane are as yet unknown. By contrast, the mechanisms that govern the uptake of exogenous fatty acids are well established in E. coli (Dirusso \& Black, 2004). When the cell encounters long-chain fatty acids in the environment, these bind to outer-membrane protein FadL and via a ligand-induced conformational shift within the protein, are transported into the periplasmic space. The more acidified environment of the periplasmic space promotes the formation of uncharged fatty acid molecules, which partition into and flip across the inner membrane. Within the cytosol, the acyl-CoA synthase FadD partitions into the inner membrane, where it functions in the vectorial esterification of the long-chain fatty acids (Dirusso \& Black, 2004). Consistent with the importance of lipid uptake, M. tuberculosis possesses numerous homologues of FadD proteins (Trivedi et al., 2004).

\section{Transporters of phosphorus-containing solutes}

Phosphorus is indispensable for energy supply, the biosynthesis of nucleic acids and phospholipids, and many other cellular processes. While inorganic phosphate is the preferred source of phosphorus, many bacteria can also take up organic phosphates and release phosphate by the action of periplasmic phosphatases such as PhoA. Gramnegative bacteria employ sophisticated transport mechanisms to acquire phosphorus-containing nutrients from the environment. E. coli uses four phosphate transport systems, Pst, Pit, GlpT and UhpT, to translocate inorganic phosphate across the inner membrane (van Veen, 1997). Part of the Pst system is the periplasmic protein PstS, which binds to and transfers phosphate to the transmembrane components PstA and PstC. PstB hydrolyses ATP and delivers energy for phosphate translocation across the inner membrane by PstA/PstC. Pst systems bind and transport phosphate with binding constants and apparent transport $K_{\mathrm{m}}$ values in the submicromolar range. $M$. tuberculosis contains several copies of the genes encoding the Pst system (Braibant et al., 1996). Two Pst components, PstS1 and PstS2, have been shown to be virulence factors in M. tuberculosis (Peirs et al., 2005; Sassetti \& Rubin, 2003). Further, M. tuberculosis contains two genes, pitA and pitB, which encode putative constitutive inorganic phosphate transporters (Content et al., 2005). The physiological role of the Pit transporters is unclear.

The single pstSCAB operon of the fast-growing $M$. smegmatis encodes a high-affinity Pst system with an apparent $K_{\mathrm{m}}$ value of $40 \mu \mathrm{M}$ phosphate. A second highaffinity phosphate uptake system of $M$. smegmatis is encoded by the phnDCE operon (Gebhard et al., 2006). However, even a $p h n D$ pstS double mutant did not show a reduced phosphate uptake, suggesting the presence of a third high-affinity phosphate uptake system of $M$. smegmatis (Gebhard et al., 2006). Considering the presence 
of three high-affinity phosphate uptake systems that are inducible at low phosphate concentration in M. smegmatis, it is unclear why a $p s t B$ mutant showed reduced phosphate transport (Bhatt et al., 2000). Taken together, these results underline the importance of phosphate uptake for mycobacteria. The transcriptional profiles of M. tuberculosis and Salmonella enterica in infected macrophages revealed that the proteins involved in inorganic phosphate transport are upregulated (Eriksson et al., 2003; Schnappinger et al., 2003), indicating that phosphate levels inside phagosomes of macrophages are indeed limited. Consistent with this conclusion, genes encoding efficient phosphate transport systems were found to be essential for the survival of M. tuberculosis in macrophages and mice (Rengarajan et al., 2005; Sassetti \& Rubin, 2003). However, it is unknown how inorganic or organic phosphates cross the outer membrane of $M$. tuberculosis. Since direct diffusion of phosphates through model lipid membranes is extremely slow [permeability coefficient of the monoanion $5 \times 10^{-12} \mathrm{~cm} \mathrm{~s}^{-1}$ (Chakrabarti \& Deamer, 1992)] it appears likely that slowly growing mycobacteria also use outer-membrane pore proteins for uptake of phosphate. Indeed, the existence of a porin with anion specificity has been demonstrated (Lichtinger et al., 1999). This porin still awaits discovery.

\section{Transporters of sulfur-containing solutes}

Sulfur is essential in cells for biological activities such as translation initiation and maintenance of the redox potential. Transposon insertions in the $c y s A$ and subI genes of $M$. bovis BCG yielded methionine auxotrophs. These mutants were resistant to chromate and did not take up sulfate. These results identified the products of the genes cysTWA and subI as components of a sulfate permease and indicated that this transporter is the sole sulfate transporter of M. bovis BCG (McAdam et al., 1995; Wooff et al., 2002). The sensitivity of sulfate uptake to azide and 1,3dicyclohexylcarbodiimide are characteristic of $\mathrm{ABC}$ transporters. Survival of the $c y s A$ and $s u b I$ mutants in mice was not different from wild-type M. bovis BCG. This indicated that, in the host, methionine may be a more important sulfur source than sulfate for growth of the $M$. tuberculosis complex. This may also explain how Mycobacterium leprae remains a pathogen, despite being a natural methionine auxotroph because of its loss of cysTWA for sulfate transport (Wood, 1995). An alternative explanation may be that other putative sulfate transporters such as the predicted sulfate permease (SulP) of M. tuberculosis are induced in vivo and compensate for the loss of the CysTWA transporter (Content et al., 2005).

\section{Transporters of nitrogen-containing solutes}

Nitrogen is an essential component of nearly all complex macromolecules in a bacterial cell, such as proteins, nucleic acids and cell wall components. Ammonium is the preferred nitrogen source of many bacteria. In enteric bacteria, diffusion of uncharged ammonia $\left(\mathrm{NH}_{3}\right)$ through the cytoplasmic membrane into the cell is sufficient to support growth in the presence of high amounts of ammonium $\left(\mathrm{NH}_{4}^{+}\right)$in the growth medium. Only when diffusion across the cell envelope becomes limiting for growth is the ammonium transporter AmtB synthesized. Homologues of AmtB exist in $M$. tuberculosis and $M$. smegmatis (Nolden et al., 2001). However, no biochemical data are available for ammonium uptake by mycobacteria and the role of $A m t B$ in this process.

Nitric oxide $(\mathrm{NO})$ is generated in large amounts within macrophages and restricts the growth of M. tuberculosis. Nitrate can be produced by oxidation of nitric oxide and is an alternative source of nitrogen for bacteria within the human host. Early work in E. coli had suggested that narK was involved only in nitrite export (Rowe et al., 1994), and so the homologous narK2 in M. tuberculosis was annotated as a 'nitrite extrusion protein'. More recent work with an $E$. coli narK narU double mutant indicated that the two proteins could transport nitrate into and nitrite out of the cell (Clegg et al., 2002; Jia \& Cole, 2005). In M. tuberculosis, four genes, narK1 through narK3 and narU, are homologous to E. coli narK and narU. Since M. tuberculosis is unable to reduce nitrite, which could accumulate to toxic levels, it must then be exported out of the cell. The M. tuberculosis narK2 was shown to complement this E. coli double mutant, supporting a role for narK2 in nitrate reduction by coding for a transporter of nitrate into and nitrite out of the cell (Sohaskey \& Wayne, 2003). Nitrate reduction by $M$. tuberculosis is regulated by control of nitrate transport into the cell by NarK2. It is proposed that NarK2 senses the redox state of the cell, possibly by monitoring the flow of electrons to cytochrome oxidase, and adjusts its activity so that nitrate is transported under reducing, but not under oxidizing, conditions (Sohaskey, 2005). Inhibition of nitrate transport by oxygen has been documented in other bacteria (Moir \& Wood, 2001). It is intriguing that M. tuberculosis, classified as an obligate aerobe, should have such intricate control of an anaerobic enzyme system. Transcription of narK2 is controlled by DosR/DevR, which responds to hypoxia and NO (Ohno et al., 2003; Voskuil et al., 2003). Both the transcription of the narK2 gene and the activity of NarK2 are controlled by similar signals (Sohaskey, 2005).

\section{Transporters of inorganic cations}

Metal ions such as $\mathrm{Fe}^{2+} / \mathrm{Fe}^{3+}, \mathrm{Cu}^{+} / \mathrm{Cu}^{2+}$ and $\mathrm{Zn}^{2+}$ play structural and catalytic roles in metalloenzymes. Genome analysis of $M$. tuberculosis revealed 28 genes encoding a broad repertoire of putative metal ion transporters. They comprise eight families of secondary active transporters and three families of primary active transporters, including twelve 'P'-type ATPases, and represent approximately a quarter of all transporters in this organism. Potential metal ion specificities include $\mathrm{K}^{+}, \mathrm{Na}^{+}, \mathrm{Cu}^{2+}, \mathrm{Cd}^{2+}, \mathrm{Zn}^{2+}$, $\mathrm{Mn}^{2+}, \mathrm{Mg}^{2+}, \mathrm{Ca}^{2+}, \mathrm{Co}^{2+}, \mathrm{Ni}^{2+}, \mathrm{Fe}^{2+/ 3+}, \mathrm{Hg}^{2+}, \mathrm{AsO}_{2}^{-}$ and $\mathrm{AsO}_{4}^{3-}$. Seventeen of these transporters are also 
encoded as complete open reading frames in M. leprae, suggesting a role in intracellular survival. The properties of these transporters, including the NRAMP orthologue $\mathrm{MntH}$, which transports manganese ions in other bacteria, have been reviewed recently (Agranoff \& Krishna, 2004; Content et al., 2005). Here we summarize only the new findings for the uptake of iron by M. tuberculosis.

Throughout the living world, iron is contained in the active centres of most redox enzymes. Because iron occurs in the insoluble $\mathrm{Fe}^{3+}$ form under oxic conditions $\left(10^{-9} \mathrm{M} \mathrm{Fe}^{3+}\right.$ in soil and water) (Ratledge \& Dover, 2000), proteins and siderophores with high binding affinity are required to make $\mathrm{Fe}^{3+}$ biologically available. M. tuberculosis produces salicylate-containing siderophores named mycobactins. The more polar form (carboxymycobactin) is released into the medium, whereas the less polar form (mycobactin) remains cell-associated (Ratledge \& Dover, 2000). Upon binding by siderophores, $\mathrm{Fe}^{3+}$ is transported into the bacterium and released from the siderophore, possibly by reduction. In most bacteria, $\mathrm{Fe}^{3+}$-siderophore complexes bind to specific receptor proteins on the cell surface and are actively transported into the cytoplasm by specialized proteins that belong to the family of $\mathrm{ABC}$ transporters (Braun \& Killmann, 1999). The ABC transporter IrtAB is required by $M$. tuberculosis to replicate in iron-deficient medium and to use $\mathrm{Fe}^{3+}$-carboxymycobactin as an iron source, indicating that IrtAB is involved in the transport of $\mathrm{Fe}^{3+}$-carboxymycobactin (Rodriguez \& Smith, 2006). Deletion of the $\operatorname{irt} A B$ genes also reduced the ability of $M$. tuberculosis to survive in macrophages and in the lungs of mice. However, the lack of $\operatorname{irt} A B$ does not completely eliminate replication of $M$. tuberculosis in iron-deficient conditions, which indicates that other transporters can partially compensate for the lack of IrtAB (Rodriguez \& Smith, 2006). Given the importance of iron, this is not surprising because pathogenic bacteria often have multiple pathways for iron acquisition. The genome of $M$. tuberculosis does not reveal other obvious siderophore transporters (Rodriguez, 2006). However, there are numerous ABC transporters for which the substrates are unknown; one or more of these could contribute to iron uptake.

\section{Transporters of amino acids}

Many micro-organisms use amino acids as a source of energy and/or nitrogen, and also for biosynthetic purposes. It was shown early in seminal papers by Yabu that D-amino acids are taken up rapidly by mycobacteria while the Lforms are transported at a much lower rate (Yabu, 1967, 1970, 1971). These results can be attributed to the specificity of the inner-membrane transporters for the natural form of amino acids. It was also found early on that M. tuberculosis cannot utilize amino acids to support metabolism, in contrast to saprophytic mycobacteria (Edson, 1951). Nevertheless, some amino acids are taken up by M. tuberculosis and M. bovis BCG (Seth \& Connell, 2000). In particular, uptake of arginine was examined because arginine also plays an important role in the cellular immune response as the substrate of the inducible nitric oxide synthase (iNOS), which generates nitric oxide to kill bacterial and parasitic pathogens in macrophages (Chan et al., 2001; Nathan \& Shiloh, 2000). Thus, competition between the pathogen and macrophages for arginine has been suggested to contribute to the outcome of infection (Mills, 2001). Not surprisingly, M. tuberculosis has several genes encoding putative L-arginine uptake transporters: Rv0522, Rv1979c, Rv1999c, Rv2320c and Rv3253c (Cole et al., 1998). Transport of L-arginine, but not of L-lysine and L-ornithine, was reduced by $70 \%$ in a mutant of $M$. bovis BCG lacking the gene homologous to $r v 0522$. This identified Rv0522 (GabP) as an arginine transporter of $M$. tuberculosis (Seth \& Connell, 2000). The remaining $30 \%$ of L-arginine transport activity and the uptake of other cationic amino acids by the mutant are probably mediated by other amino acid permeases.

\section{Conclusions}

It is apparent that the uptake of nutrients by mycobacteria is not well understood, despite its importance for understanding the physiology and pathogenicity of $M$. tuberculosis and the availability of a wealth of genomic information. The knowledge gap begins with the uncertainty about which are the main essential nutrients of M. tuberculosis inside the host. This obviously depends on the location of $M$. tuberculosis inside the human body, which may vary from phagosomes in macrophages and dendritic cells (Russell, 2003) to granulomas (Ulrichs \& Kaufmann, 2006) and even fat cells (Neyrolles et al., 2006). There is clearly a need to determine the nutrients available in those different environments and to identify the proteins that are employed by $M$. tuberculosis to take up these nutrients. A solid functional, biochemical and structural analysis of these membrane proteins is a prerequisite to understanding the transport processes across both the inner and outer membrane of M. tuberculosis. Comparisons with the saprophyte $M$. smegmatis are not expected to contribute much to understanding the physiology and virulence of $M$. tuberculosis. However, studying nutrient uptake pathways in $M$. smegmatis should reveal the principal mechanisms by which the permeability barriers in mycobacteria can be overcome. Examples are presented in this review. It is striking that M. tuberculosis uses far fewer carbohydrate transporters than M. smegmatis. Further, the set of outer-membrane porins is apparently also different. These differences probably represent adaptations of M. tuberculosis to its slower growth (Cox \& Cook, 2007) and to its very different natural habitat.

The comprehensive identification and the biochemical and structural characterization of the nutrient transporters of $M$. tuberculosis will not only promote our understanding of the physiology of this important human pathogen, but might also be exploited to improve tuberculosis chemotherapy. In particular, outer-membrane proteins 
offer the tremendous advantage as drug targets that inhibitors may not need to cross the outer membrane, which is an extremely efficient permeability barrier in mycobacteria. In addition, they are likely to represent novel drug targets because they do not appear to show any similarity to other proteins (Faller et al., 2004). It is my hope that this review will stimulate experimental work to examine nutrient transport pathways in mycobacteria.

\section{Acknowledgements}

I thank all present and past members of the Mycolab for excellent contributions and stimulating discussions. In particular, I thank Jason Huff for thoughtfully editing the manuscript. The anonymous reviewers deserve credit for valuable suggestions about how to improve the manuscript. Sequence data for Mycobacterium smegmatis were obtained from The Institute for Genomic Research website (http://www.tigr.org). This work was supported by grant AI063432 of the National Institutes of Health.

\section{References}

Agranoff, D. \& Krishna, S. (2004). Metal ion transport and regulation in Mycobacterium tuberculosis. Front Biosci 9, 2996-3006.

Barry, C. E., III, Lee, R. E., Mdluli, K., Sampson, A. E., Schroeder, B. G., Slayden, R. A. \& Yuan, Y. (1998). Mycolic acids: structure, biosynthesis and physiological functions. Prog Lipid Res 37, 143-179.

Bell, A. W., Buckel, S. D., Groarke, J. M., Hope, J. N., Kingsley, D. H. \& Hermodson, M. A. (1986). The nucleotide sequences of the $r b s D$, $r b s A$, and $r b s C$ genes of Escherichia coli K12. J Biol Chem 261, 7652-7658.

Bentley, S. D., Chater, K. F., Cerdeno-Tarraga, A. M., Challis, G. L., Thomson, N. R., James, K. D., Harris, D. E., Quail, M. A., Kieser, H. \& other authors (2002). Complete genome sequence of the model actinomycete Streptomyces coelicolor A3(2). Nature 417, 141-147.

Bertram, R., Schlicht, M., Mahr, K., Nothaft, H., Saier, M. H., Jr \& Titgemeyer, F. (2004). In silico and transcriptional analysis of carbohydrate uptake systems of Streptomyces coelicolor A3(2). J Bacteriol 186, 1362-1373.

Beveridge, T. J. (1995). The periplasmic space and the periplasm in Gram-positive and Gram-negative bacteria. ASM News 61, 125-130.

Beveridge, T. J. (1999). Structures of gram-negative cell walls and their derived membrane vesicles. J Bacteriol 181, 4725-4733.

Beveridge, T. J. \& Kadurugamuwa, J. L. (1996). Periplasm, periplasmic spaces, and their relation to bacterial wall structure: novel secretion of selected periplasmic proteins from Pseudomonas aeruginosa. Microb Drug Resist 2, 1-8.

Bhatt, K., Banerjee, S. K. \& Chakraborti, P. K. (2000). Evidence that phosphate specific transporter is amplified in a fluoroquinolone resistant Mycobacterium smegmatis. Eur J Biochem 267, 4028-4032.

Borich, S. M., Murray, A. \& Gormley, E. (2000). Genomic arrangement of a putative operon involved in maltose transport in the Mycobacterium tuberculosis complex and Mycobacterium leprae. Microbios 102, 7-15.

Braibant, M., Lefevre, P., de Wit, L., Peirs, P., Ooms, J., Huygen, K., Andersen, A. B. \& Content, J. (1996). A Mycobacterium tuberculosis gene cluster encoding proteins of a phosphate transporter homologous to the Escherichia coli Pst system. Gene 176, 171-176.

Braibant, M., Gilot, P. \& Content, J. (2000). The ATP binding cassette (ABC) transport systems of Mycobacterium tuberculosis. FEMS Microbiol Rev 24, 449-467.
Braun, V. \& Killmann, H. (1999). Bacterial solutions to the iron-supply problem. Trends Biochem Sci 24, 104-109.

Brennan, P. J. \& Nikaido, H. (1995). The envelope of mycobacteria. Annu Rev Biochem 64, 29-63.

Brinkkötter, A., Kloss, H., Alpert, C. \& Lengeler, J. W. (2000). Pathways for the utilization of $\mathrm{N}$-acetylgalactosamine and galactosamine in Escherichia coli. Mol Microbiol 37, 125-135.

Chakrabarti, A. C. \& Deamer, D. W. (1992). Permeability of lipid bilayers to amino acids and phosphate. Biochim Biophys Acta 1111, 171-177.

Chan, E. D., Chan, J. \& Schluger, N. W. (2001). What is the role of nitric oxide in murine and human host defense against tuberculosis? Current knowledge. Am J Respir Cell Mol Biol 25, 606-612.

Clegg, S., Yu, F., Griffiths, L. \& Cole, J. A. (2002). The roles of the polytopic membrane proteins NarK, NarU and NirC in Escherichia coli K-12: two nitrate and three nitrite transporters. Mol Microbiol 44, 143-155.

Cole, S. T., Brosch, R., Parkhill, J., Garnier, T., Churcher, C., Harris, D., Gordon, S. V., Eiglmeier, K., Gas, S. \& other authors (1998). Deciphering the biology of Mycobacterium tuberculosis from the complete genome sequence. Nature 393, 537-544.

Content, J., Braibant, M., Connell, N. \& Ainsa, J. A. (2005). Transport processes. In Tuberculosis and the Tubercle Bacillus, pp. 379-401. Edited by S. Cole, K. D. Eisenach, D. N. McMurray \& W. R. Jacobs. Washington, DC: ASM Press.

Cox, R. A. \& Cook, G. M. (2007). Growth regulation in the mycobacterial cell. Curr Mol Med 7, 231-245.

Daffé, M. \& Draper, P. (1998). The envelope layers of mycobacteria with reference to their pathogenicity. Adv Microb Physiol 39, 131-203.

Daley, D. O., Rapp, M., Granseth, E., Melen, K., Drew, D. \& von Heijne, G. (2005). Global topology analysis of the Escherichia coli inner membrane proteome. Science 308, 1321-1323.

Dirusso, C. C. \& Black, P. N. (2004). Bacterial long chain fatty acid transport: gateway to a fatty acid-responsive signaling system. J Biol Chem 279, 49563-49566.

Draper, P. (1998). The outer parts of the mycobacterial envelope as permeability barriers. Front Biosci 3, D1253-D1261.

Dubnau, E., Chan, J., Mohan, V. P. \& Smith, I. (2005). Responses of Mycobacterium tuberculosis to growth in the mouse lung. Infect Immun 73, 3754-3757.

Dumas, F., Koebnik, R., Winterhalter, M. \& van Gelder, P. (2000). Sugar transport through maltoporin of Escherichia coli. Role of polar tracks. J Biol Chem 275, 19747-19751.

Edson, N. L. (1951). The intermediary metabolism of the mycobacteria. Bacteriol Rev 15, 147-182.

Eriksson, S., Lucchini, S., Thompson, A., Rhen, M. \& Hinton, J. C. (2003). Unravelling the biology of macrophage infection by gene expression profiling of intracellular Salmonella enterica. Mol Microbiol 47, 103-118.

Etienne, G., Laval, F., Villeneuve, C., Dinadayala, P., Abouwarda, A., Zerbib, D., Galamba, A. \& Daffe, M. (2005). The cell envelope structure and properties of Mycobacterium smegmatis $\mathrm{mc}^{2} 155$ : is there a clue for the unique transformability of the strain? Microbiology 151, 2075-2086.

Eze, M. O. \& McElhaney, R. N. (1981). The effect of alterations in the fluidity and phase state of the membrane lipids on the passive permeation and facilitated diffusion of glycerol in Escherichia coli. J Gen Microbiol 124, 299-307.

Faller, M., Niederweis, M. \& Schulz, G. E. (2004). The structure of a mycobacterial outer-membrane channel. Science 303, 1189-1192. 
Franke, W. \& Schillinger, A. (1944). Zum Stoffwechsel der saeurefesten Bakterien. I. Orientierende aerobe Reihenversuche. Biochem Z 319, 313-334 (in German).

Gebhard, S., Tran, S. L. \& Cook, G. M. (2006). The Phn system of Mycobacterium smegmatis: a second high-affinity ABC-transporter for phosphate. Microbiology 152, 3453-3465.

Graham, L. L., Beveridge, T. J. \& Nanninga, N. (1991). Periplasmic space and the concept of the periplasm. Trends Biochem Sci 16, 328-329.

Gutknecht, R., Beutler, R., Garcia-Alles, L. F., Baumann, U. \& Erni, B. (2001). The dihydroxyacetone kinase of Escherichia coli utilizes a phosphoprotein instead of ATP as phosphoryl donor. EMBO J 20, 2480-2486.

Hancock, R. E., Farmer, S. W., Li, Z. S. \& Poole, K. (1991). Interaction of aminoglycosides with the outer membranes and purified lipopolysaccharide and $\mathrm{OmpF}$ porin of Escherichia coli. Antimicrob Agents Chemother 35, 1309-1314.

Hoffmann, C., Leis, L., Niederweis, M., Plitzko, J. M. \& Engelhardt, H. (2008). Disclosure of the mycobacterial outer membrane: cryoelectron tomography and vitreous sections reveal the lipid bilayer structure. Proc Natl Acad Sci U S A (in press).

Izumori, K., Yamanaka, K. \& Elbein, D. (1976). Pentose metabolism in Mycobacterium smegmatis: specificity of induction of pentose isomerases. J Bacteriol 128, 587-591.

Jackson, M., Stadthagen, G. \& Gicquel, B. (2007). Long-chain multiple methyl-branched fatty acid-containing lipids of Mycobacterium tuberculosis: biosynthesis, transport, regulation and biological activities. Tuberculosis 87, 78-86.

Jarlier, V. \& Nikaido, H. (1990). Permeability barrier to hydrophilic solutes in Mycobacterium chelonei. J Bacteriol 172, 1418-1423.

Jia, W. \& Cole, J. A. (2005). Nitrate and nitrite transport in Escherichia coli. Biochem Soc Trans 33, 159-161.

Kana, B. D. \& Mizrahi, V. (2004). Molecular genetics of Mycobacterium tuberculosis in relation to the discovery of novel drugs and vaccines. Tuberculosis 84, 63-75.

Kartmann, B., Stenger, S. \& Niederweis, M. (1999). Porins in the cell wall of Mycobacterium tuberculosis. J Bacteriol 181, 6543-6546. (Authors' correction in J Bacteriol 181, 7650)

Koch, R. (1882). Die Aetiologie der Tuberculose. Berliner Klinische Wochenzeitschrift 19,18 (in German).

Koebnik, R., Locher, K. P. \& van Gelder, P. (2000). Structure and function of bacterial outer membrane proteins: barrels in a nutshell. Mol Microbiol 37, 239-253.

Lichtinger, T., Heym, B., Maier, E., Eichner, H., Cole, S. T. \& Benz, R. (1999). Evidence for a small anion-selective channel in the cell wall of Mycobacterium bovis BCG besides a wide cation-selective pore. FEBS Lett 454, 349-355.

Liu, J., Rosenberg, E. Y. \& Nikaido, H. (1995). Fluidity of the lipid domain of cell wall from Mycobacterium chelonae. Proc Natl Acad Sci U S A 92, 11254-11258.

Liu, J., Barry, C. E., III, Besra, G. S. \& Nikaido, H. (1996). Mycolic acid structure determines the fluidity of the mycobacterial cell wall. $J$ Biol Chem 271, 29545-29551.

Machowski, E. E., Dawes, S. \& Mizrahi, V. (2005). TB tools to tell the tale - molecular genetic methods for mycobacterial research. Int $J$ Biochem Cell Biol 37, 54-68.

Mahfoud, M., Sukumaran, S., Hülsmann, P., Grieger, K. \& Niederweis, M. (2006). Topology of the porin MspA in the outer membrane of Mycobacterium smegmatis. J Biol Chem 281, 5908-5915.

Maier, C., Bremer, E., Schmid, A. \& Benz, R. (1988). Pore-forming activity of the Tsx protein from the outer membrane of Escherichia coli. Demonstration of a nucleoside-specific binding site. J Biol Chem 263, 2493-2499.

Matias, V. R. \& Beveridge, T. J. (2005). Cryo-electron microscopy reveals native polymeric cell wall structure in Bacillus subtilis 168 and the existence of a periplasmic space. Mol Microbiol 56, 240-251.

Matias, V. R. \& Beveridge, T. J. (2006). Native cell wall organization shown by cryo-electron microscopy confirms the existence of a periplasmic space in Staphylococcus aureus. J Bacteriol 188, 1011-1021.

Matias, V. R., Al-Amoudi, A., Dubochet, J. \& Beveridge, T. J. (2003). Cryo-transmission electron microscopy of frozen-hydrated sections of Escherichia coli and Pseudomonas aeruginosa. J Bacteriol 185, 6112-6118.

McAdam, R. A., Weisbrod, T. R., Martin, J., Scuderi, J. D., Brown, A. M., Cirillo, J. D., Bloom, B. R. \& Jacobs, W. R., Jr (1995). In vivo growth characteristics of leucine and methionine auxotrophic mutants of Mycobacterium bovis BCG generated by transposon mutagenesis. Infect Immun 63, 1004-1012.

McKinney, J. D., Honer zu Bentrup, K., Munoz-Elias, E. J., Miczak, A., Chen, B., Chan, W. T., Swenson, D., Sacchettini, J. C., Jacobs, W. R., Jr \& Russell, D. G. (2000). Persistence of Mycobacterium tuberculosis in macrophages and mice requires the glyoxylate shunt enzyme isocitrate lyase. Nature 406, 735-738.

Mills, C. D. (2001). Macrophage arginine metabolism to ornithine/ urea or nitric oxide/citrulline: a life or death issue. Crit Rev Immunol 21, 399-425

Mineda, T., Ohara, N., Yukitake, H. \& Yamada, T. (1998). The ribosomes contents of mycobacteria. New Microbiol 21, 1-7.

Minnikin, D. E. (1982). Lipids: complex lipids, their chemistry, biosynthesis and roles. In The Biology of the Mycobacteria: Physiology, Identification and Classification, pp. 95-184. Edited by C. Ratledge \& J. Stanford. London: Academic Press.

Moir, J. W. \& Wood, N. J. (2001). Nitrate and nitrite transport in bacteria. Cell Mol Life Sci 58, 215-224.

Molle, V., Saint, N., Campagna, S., Kremer, L., Lea, E., Draper, P. \& Molle, G. (2006). pH-dependent pore-forming activity of OmpATb from Mycobacterium tuberculosis and characterization of the channel by peptidic dissection. Mol Microbiol 61, 826-837.

Munoz-Elias, E. J. \& McKinney, J. D. (2005). Mycobacterium tuberculosis isocitrate lyases 1 and 2 are jointly required for in vivo growth and virulence. Nat Med 11, 638-644.

Murphy, H. N., Stewart, G. R., Mischenko, V. V., Apt, A. S., Harris, R., McAlister, M. S., Driscoll, P. C., Young, D. B. \& Robertson, B. D. (2005). The OtsAB pathway is essential for trehalose biosynthesis in Mycobacterium tuberculosis. J Biol Chem 280, 14524-14529.

Nathan, C. \& Shiloh, M. U. (2000). Reactive oxygen and nitrogen intermediates in the relationship between mammalian hosts and microbial pathogens. Proc Natl Acad Sci U S A 97, 8841-8848.

Neyrolles, O., Hernandez-Pando, R., Pietri-Rouxel, F., Pietri-Rouxel, F., Fornès, P., Tailleux, L., Barrios Payán, J. A., Pivert, E., Bordat, Y., Aguilar, D. \& other authors (2006). Is adipose tissue a place for Mycobacterium tuberculosis persistence? PLoS ONE 1, e43.

Niederweis, M. (2003). Mycobacterial porins - new channel proteins in unique outer membranes. Mol Microbiol 49, 1167-1177.

Niederweis, M., Ehrt, S., Heinz, C., Klöcker, U., Karosi, S., Swiderek, K. M., Riley, L. W. \& Benz, R. (1999). Cloning of the mspA gene encoding a porin from Mycobacterium smegmatis. Mol Microbiol 33, 933-945.

Nikaido, H. (1994). Porins and specific diffusion channels in bacterial outer membranes. J Biol Chem 269, 3905-3908.

Nikaido, H. (2003). Molecular basis of bacterial outer membrane permeability revisited. Microbiol Mol Biol Rev 67, 593-656. 
Nikaido, H., Rosenberg, E. Y. \& Foulds, J. (1983). Porin channels in Escherichia coli: studies with beta-lactams in intact cells. J Bacteriol 153, 232-240.

Nikaido, H., Kim, S. H. \& Rosenberg, E. Y. (1993). Physical organization of lipids in the cell wall of Mycobacterium chelonae. Mol Microbiol 8, 1025-1030.

Nolden, L., Ngouoto-Nkili, C. E., Bendt, A. K., Kramer, R. \& Burkovski, A. (2001). Sensing nitrogen limitation in Corynebacterium glutamicum: the role of $g \ln K$ and $g \operatorname{lnD}$. Mol Microbiol 42, 1281-1295.

Nothaft, H., Dresel, D., Willimek, A., Mahr, K., Niederweis, M. \& Titgemeyer, F. (2003). The phosphotransferase system of Streptomyces coelicolor is biased for $\mathrm{N}$-acetylglucosamine metabolism. J Bacteriol 185, 7019-7023.

Ohno, H., Zhu, G., Mohan, V. P., Chu, D., Kohno, S., Jacobs, W. R., Jr \& Chan, J. (2003). The effects of reactive nitrogen intermediates on gene expression in Mycobacterium tuberculosis. Cell Microbiol 5, 637-648.

Paul, T. R. \& Beveridge, T. J. (1992). Reevaluation of envelope profiles and cytoplasmic ultrastructure of mycobacteria processed by conventional embedding and freeze-substitution protocols. J Bacteriol 174, 6508-6517.

Paul, T. R. \& Beveridge, T. J. (1994). Preservation of surface lipids and determination of ultrastructure of Mycobacterium kansasii by freezesubstitution. Infect Immun 62, 1542-1550.

Paula, S., Volkov, A. G., Van Hoek, A. N., Haines, T. H. \& Deamer, D. W. (1996). Permeation of protons, potassium ions, and small polar molecules through phospholipid bilayers as a function of membrane thickness. Biophys J 70, 339-348.

Peirs, P., Lefevre, P., Boarbi, S., Wang, X. M., Denis, O., Braibant, M., Pethe, K., Locht, C., Huygen, K. \& Content, J. (2005). Mycobacterium tuberculosis with disruption in genes encoding the phosphate binding proteins PstS1 and PstS2 is deficient in phosphate uptake and demonstrates reduced in vivo virulence. Infect Immun 73, 1898-1902.

Ramakrishnan, T., Murthy, P. S. \& Gopinathan, K. P. (1972). Intermediary metabolism of mycobacteria. Bacteriol Rev 36, 65-108.

Ratledge, C. (1982). Nutrition, growth and metabolism. In The Biology of the Mycobacteria, pp. 186-212. Edited by C. Ratledge \& J. Stanford. London: Academic Press.

Ratledge, C. \& Dover, L. G. (2000). Iron metabolism in pathogenic bacteria. Annu Rev Microbiol 54, 881-941.

Raynaud, C., Guilhot, C., Rauzier, J., Bordat, Y., Pelicic, V., Manganelli, R., Smith, I., Gicquel, B. \& Jackson, M. (2002a). Phospholipases $\mathrm{C}$ are involved in the virulence of Mycobacterium tuberculosis. Mol Microbiol 45, 203-217.

Raynaud, C., Papavinasasundaram, K. G., Speight, R. A., Springer, B., Sander, P., Böttger, E. C., Colston, M. J. \& Draper, P. (2002b). The functions of OmpATb, a pore-forming protein of Mycobacterium tuberculosis. Mol Microbiol 46, 191-201.

Rengarajan, J., Bloom, B. R. \& Rubin, E. J. (2005). Genome-wide requirements for Mycobacterium tuberculosis adaptation and survival in macrophages. Proc Natl Acad Sci U S A 102, 8327-8332.

Rimmele, M. \& Boos, W. (1994). Trehalose-6-phosphate hydrolase of Escherichia coli. J Bacteriol 176, 5654-5664.

Rodriguez, G. M. (2006). Control of iron metabolism in Mycobacterium tuberculosis. Trends Microbiol 14, 320-327.

Rodriguez, G. M. \& Smith, I. (2006). Identification of an ABC transporter required for iron acquisition and virulence in Mycobacterium tuberculosis. J Bacteriol 188, 424-430.

Rowe, J. J., Ubbink-Kok, T., Molenaar, D., Konings, W. N. \& Driessen, A. J. (1994). NarK is a nitrite-extrusion system involved in anaerobic nitrate respiration by Escherichia coli. Mol Microbiol 12, 579-586.
Russell, D. G. (2003). Phagosomes, fatty acids and tuberculosis. Nat Cell Biol 5, 776-778.

Sa-Nogueira, I., Nogueira, T. V., Soares, S. \& de Lencastre, H. (1997). The Bacillus subtilis L-arabinose (ara) operon: nucleotide sequence, genetic organization and expression. Microbiology 143, 957-969.

Sassetti, C. M. \& Rubin, E. J. (2003). Genetic requirements for mycobacterial survival during infection. Proc Natl Acad Sci U S A 100, 12989-12994.

Schnappinger, D., Ehrt, S., Voskuil, M. I., Liu, Y., Mangan, J. A., Monahan, I. M., Dolganov, G., Efron, B., Butcher, P. D. \& other authors (2003). Transcriptional adaptation of Mycobacterium tuberculosis within macrophages: insights into the phagosomal environment. J Exp Med 198, 693-704.

Schönert, S., Buder, T. \& Dahl, M. K. (1999). Properties of maltoseinducible alpha-glucosidase MalL (sucrase-isomaltase-maltase) in Bacillus subtilis: evidence for its contribution to maltodextrin utilization. Res Microbiol 150, 167-177.

Senaratne, R. H., Mobasheri, H., Papavinasasundaram, K. G., Jenner, P., Lea, E. J. \& Draper, P. (1998). Expression of a gene for a porin-like protein of the OmpA family from Mycobacterium tuberculosis H37Rv. J Bacteriol 180, 3541-3547.

Seth, A. \& Connell, N. D. (2000). Amino acid transport and metabolism in mycobacteria: cloning, interruption, and characterization of an L-Arginine/gamma-aminobutyric acid permease in Mycobacterium bovis BCG. J Bacteriol 182, 919-927.

Sohaskey, C. D. (2005). Regulation of nitrate reductase activity in Mycobacterium tuberculosis by oxygen and nitric oxide. Microbiology 151, 3803-3810.

Sohaskey, C. D. \& Wayne, L. G. (2003). Role of narK2X and narGHJI in hypoxic upregulation of nitrate reduction by Mycobacterium tuberculosis. J Bacteriol 185, 7247-7256.

Sørensen, K. I. \& Hove-Jensen, B. (1996). Ribose catabolism of Escherichia coli: characterization of the $r p i B$ gene encoding ribose phosphate isomerase $\mathrm{B}$ and of the rpiR gene, which is involved in regulation of rpiB expression. J Bacteriol 178, 1003-1011.

Stahl, C., Kubetzko, S., Kaps, I., Seeber, S., Engelhardt, H. \& Niederweis, M. (2001). MspA provides the main hydrophilic pathway through the cell wall of Mycobacterium smegmatis. Mol Microbiol 40, 451-464. (Authors' correction in Mol Microbiol 457, 1509)

Stephan, J., Bender, J., Wolschendorf, F., Hoffmann, C., Roth, E., Mailänder, C., Engelhardt, H. \& Niederweis, M. (2005). The growth rate of Mycobacterium smegmatis depends on sufficient porinmediated influx of nutrients. Mol Microbiol 58, 714-730.

Sumiya, M., Davis, E. O., Packman, L. C., McDonald, T. P. \& Henderson, P. J. (1995). Molecular genetics of a receptor protein for D-xylose, encoded by the gene $x y l F$, in Escherichia coli. Receptors Channels 3, 117-128.

Talaue, M. T., Venketaraman, V., Hazbon, M. H., Peteroy-Kelly, M., Seth, A., Colangeli, R., Alland, D. \& Connell, N. D. (2006). Arginine homeostasis in J774.1 macrophages in the context of Mycobacterium bovis BCG infection. J Bacteriol 188, 4830-4840.

Timm, J., Post, F. A., Bekker, L. G., Walther, G. B., Wainwright, H. C., Manganelli, R., Chan, W. T., Tsenova, L., Gold, B. \& other authors (2003). Differential expression of iron-, carbon-, and oxygenresponsive mycobacterial genes in the lungs of chronically infected mice and tuberculosis patients. Proc Natl Acad Sci U S A 100, 14321-14326.

Titgemeyer, F., Amon, J., Parche, S., Mahfoud, M., Bail, J., Schlicht, M., Rehm, N., Hillmann, D., Stephan, J. \& other authors (2007). A genomic view of sugar transport in Mycobacterium smegmatis and Mycobacterium tuberculosis. J Bacteriol 189, 5903-5915. 
Trivedi, O. A., Arora, P., Sridharan, V., Tickoo, R., Mohanty, D. \& Gokhale, R. S. (2004). Enzymic activation and transfer of fatty acids as acyl-adenylates in mycobacteria. Nature 428, 441-445.

Ulrichs, T. \& Kaufmann, S. H. (2006). New insights into the function of granulomas in human tuberculosis. J Pathol 208, 261-269.

van Veen, H. W. (1997). Phosphate transport in prokaryotes: molecules, mediators and mechanisms. Antonie Van Leeuwenhoek 72, 299-315.

van Wezel, G. P., Mahr, K., Konig, M., Traag, B. A., Pimentel-Schmitt, E. F., Willimek, A. \& Titgemeyer, F. (2005). GlcP constitutes the major glucose uptake system of Streptomyces coelicolor A3(2). Mol Microbiol 55, 624-636.

Voskuil, M. I., Schnappinger, D., Visconti, K. C., Harrell, M. I., Dolganov, G. M., Sherman, D. R. \& Schoolnik, G. K. (2003). Inhibition of respiration by nitric oxide induces a Mycobacterium tuberculosis dormancy program. J Exp Med 198, 705-713.

Vyas, N. K., Vyas, M. N. \& Quiocho, F. A. (2003). Crystal structure of $M$. tuberculosis $\mathrm{ABC}$ phosphate transport receptor: specificity and charge compensation dominated by ion-dipole interactions. Structure 11, 765-774.

Webb, M. R. (2003). Mycobacterial ABC transport system: structure of the primary phosphate receptor. Structure 11, 736-738.

Wheeler, P. R., Bulmer, K. \& Ratledge, C. (1990). Enzymes for biosynthesis de novo and elongation of fatty acids in mycobacteria grown in host cells: is Mycobacterium leprae competent in fatty acid biosynthesis? J Gen Microbiol 136, 211-217.

Wolschendorf, F., Mahfoud, M. \& Niederweis, M. (2007). Porins are required for uptake of phosphates by Mycobacterium smegmatis. J Bacteriol 189, 2435-2442.

Wood, K. V. (1995). Marker proteins for gene expression. Curr Opin Biotechnol 6, 50-58.

Woodruff, P. J., Carlson, B. L., Siridechadilok, B., Pratt, M. R., Senaratne, R. H., Mougous, J. D., Riley, L. W., Williams, S. J. \& Bertozzi, C. R. (2004). Trehalose is required for growth of Mycobacterium smegmatis. J Biol Chem 279, 28835-28843.

Woodson, K. \& Devine, K. M. (1994). Analysis of a ribose transport operon from Bacillus subtilis. Microbiology 140, 1829-1838.

Wooff, E., Michell, S. L., Gordon, S. V., Chambers, M. A., Bardarov, S., Jacobs, W. R., Jr, Hewinson, R. G. \& Wheeler, P. R. (2002). Functional genomics reveals the sole sulphate transporter of the Mycobacterium tuberculosis complex and its relevance to the acquisition of sulphur in vivo. Mol Microbiol 43, 653-663.

Yabu, K. (1967). The uptake of D-glutamic acid by Mycobacterium avium. Biochim Biophys Acta 135, 181-183.

Yabu, K. (1970). Amino acid transport in Mycobacterium smegmatis. J Bacteriol 102, 6-13.

Yabu, K. (1971). Aspartic acid transport in Mycobacterium smegmatis. Jpn J Microbiol 15, 449-456. 